\title{
Energy and Emissions Analysis of Hemp Hurd and Vine Pruning Derived Pellets Used as Fuel in a Commercial Stove for Residential Heating
}

\author{
Simone Pedrazzi ${ }^{*}$, Nicolò Morselli, Marco Puglia, Paolo Tartarini \\ Dept. of Engineering “Enzo Ferrari”, University of Modena and Reggio Emilia, Via Vivarelli 10/1 - 41125 Modena, Italy
}

Corresponding Author Email: simone.pedrazzi@unimore.it

https://doi.org/10.18280/ti-ijes.642-435

Received: 12 March 2020

Accepted: 3 June 2020

\section{Keywords:}

hemp-hurd, pellet, stove, vine-prunings, combustion, pollutants

\begin{abstract}
Among the renewable sources, woody biomass combustion is still the most diffused for domestic heating and, in the last decades, domestic pellet stoves have spread widely due to their simplicity and to the high energy density of the pelletized fuel. In several regions of North Italy, the legislator limited the type of pellet fuels that can be used. Only A1-plus pellets, which is obtained from clean wood processing, is allowed. However, the abundance of residual biomasses, from vine and hemp seasonal pruning, rises the possibility of their thermal valorization in domestic pellet stoves. In this paper, hemp hurd and vine pruning derived pellets were tested as fuel into a commercial pellet stove of $9 \mathrm{~kW}$ nominal thermal power and a comparison was made in terms of combustion efficiency and pollutant emissions. On the one hand, the tests shown similar results between $\mathrm{A} 1+$ and vine pellets in terms of efficiency while the emissions of CO increased by 10-times. On the other hand, hemp derived pellets generate thermal efficiency 3-times lower than pellet A1+ and slightly higher emissions.
\end{abstract}

\section{INTRODUCTION}

Agri-pellets are not conventional fuels obtained from agricultural and forestry residues that do not have a specific use. While several studies referred to the thermochemical conversion of residual biomasses in the form of pellets or briquettes can be found in literature related to the gasification process [1-5], few studies are related to the combustion of agripellets in domestic stoves. The abundancy of residual biomasses [6-9] is sometimes higher that common fir or beech used in the standard pellet production chain, but the lack of a proper legislation and optimized supply chain suggests the disposal instead of the thermal valorization [10].

In the North of Italy, the use of agri-pellets is not allowed in small stoves or boiler with a nominal thermal power lower than $35 \mathrm{~kW}$ [11] because of the combustion behavior in not well studied. In these devices, only A1-plus wood pellets can be used as fuel thanks to the high standardization of this fuel.

In this work, hemp-hurd and vine-pruning derived pellets are tested as fuel into a commercial pellet stove of $9 \mathrm{~kW}$ nominal thermal power. Control tests with standard A1+ type and A2 type wood pellets were done. Then, three sample of hemp pellets were made with $0 \%_{\mathrm{wt}}, 15 \%_{\mathrm{wt}}$ and $30 \% \%_{\mathrm{wt}}$ of soft wood to create a stable shape and to obtain good mechanical properties. Hemp pellets were obtained using a small pelletizer. Concerning vine pruning pellets, a sample obtained from an industrial process was tested. In this case, pellets were made only with air-dried organic vine pruning bales.

Before combustion tests, ultimate analysis of each sample was done to chemically characterize the fuel and to calculate his higher heating value (HHV). The stove was instrumented with thermocouples, flow sensors and emissions analyzer able to detect $\mathrm{CO}, \mathrm{NO}, \mathrm{NO}_{\mathrm{x}}$ and $\mathrm{SO}_{2}$ gases. In each test, the thermal efficiency was calculated starting from biomass heating value and emission values were registered.

\section{MATERIALS AND METHODS}

\subsection{Agricultural residues pelletization}

To perform comparable combustion tests, the agricultural residues needed to be converted into pellets. The pelletization process can generally be subdivided into three steps:

- Wood residues drying;

- Residues shrinking and pulverization;

- Pelletization.

These steps were followed both for the vine-prunings and hemp-hurd materials with some differences that are explained in the following.

\subsubsection{Vine-prunings pelletization}

The vineyard residues are usually left on the field during the pruning process that takes place during the late winter season and to convert those residues into pellets different paths can be followed. In the current work, the process went through these steps:

- The prunings were harvested and baled using a tractor-driven baler from CAEB [12]. The process led to the formation of $600 \mathrm{~mm}(\mathrm{H}) \times 400 \mathrm{~mm} \varnothing$ bales of 25-30 kg weight.

- The bales were stored under cover during the spring and part of the summer, allowing their drying to a moisture content between 20 and $25 \%$ wb.

- Finally, the pelletization process were carried out using the EPS-Line from CAEB and standard $6 \mathrm{~mm}$ $\emptyset$ pellets were generated. 


\subsubsection{Hemp-hurd pelletization}

While for the vine-prunings the collection and pelletization process is consolidated and it could be possible to use industrial machines, for the hemp-hurd this solution was not available and, for this reason, the pelletization process was carried out on a lab scale facility and followed the steps below:

- Hemp-hurd biomass was already available in dry chunks 40-50 mm x $5 \mathrm{~mm}$ and was pulverized using an electrical grinder;

- The powder was reduced into standard $6 \mathrm{~mm}$ pellets using a $7 \mathrm{~kW}$ electricity driven pelletizer.

To test and optimize the pellet transformation of hemp-hurd chunks, some samples were made without pulverize the material and others by adding pine sawdust to the hemp-hurd, in the proportion of $15 \%$ and $30 \%$ of the total. The following table is a summary of the different sample making procedure.

Table 1. Hemp-hurd pellet making procedure

\begin{tabular}{ccc}
\hline Sample name & Pulverization & Sawdust \\
\hline HEMP15GR & YES & $15 \%$ \\
HEMP30GR & YES & $30 \%$ \\
HEMP & NO & $0 \%$ \\
HEMP15 & NO & $15 \%$ \\
\hline
\end{tabular}

\subsection{Pellet stove instrumentation}

The combustion tests showed in this paper are based on a commercial wood pellet stove with a nominal power of $9 \mathrm{~kW}_{\text {th }}$.

As represented in Figure 1a the stove consists of three main components:

- The feeding system: it is made of a $25 \mathrm{~L}$ hopper equipped with a feeding auger that regularly feeds the combustion chamber according to the thermal power demand.

- The combustion system: composed of a combustion chamber and a series of exhaust-gases/air heat exchangers to cool down the fumes and increase the efficiency of the stove.

- The cooling system: an air blower recirculates the ambient air (the room air when the stove is placed indoor) and heats it up by passing it through the heat exchangers mentioned above.

- The electronic control system regulates the power of the stove by modifying the ON/OFF periods of the feeding screw and, hence, changing the biomass feed rate.

In the paragraphs below, the different instruments are labeled with letters and numbers and reported in Figure 1.

\subsubsection{Air flowrate measurements}

Three different flows need to be considered in the comparison of the agri-pellet pellet combustion: the air flowrate of the air blower for exhaust gas cooling (A), the flowrate of the blower for the combustion air (B) and the flowrate of the biomass $(\mathrm{C})$.

The cooling air flowrate was measured by using a digital anemometer (TESTO 417 [13]) while the flowrate for combustion air was measured by using a volumetric meter.

\subsubsection{Temperature measurements}

Given the intent of calculating the efficiency comparison between different fuels, together with the flowrates, the temperatures of the different fluids were measured by means of the thermocouple datalogger TC-08 from PicoTech [14]. In particular, T-type thermocouples $1 \mathrm{~mm}$ thick were used to measure: the ambient air (1) and combustion air (2) intake temperature; the heat exchanger outlet temperature in three different position (3-5) in order to average the results; the exhaust gases temperature (6).

Finally, the flame temperature (7) was measured by placing a K-type thermocouple on a metal mesh fixed to the fireplace. The metal mesh was to keep the thermocouple tip in the same position over the tests.

\subsubsection{Emission measurements}

For each pellet combustion test, the exhaust gases emissions were measured. The instrument used is a VarioPLUS from MRU [15], which probe was placed at the end of the stove chimney (8). The concentration of $\mathrm{O}_{2}, \mathrm{CO}_{2}, \mathrm{CO}, \mathrm{NO}, \mathrm{NO}_{\mathrm{x}}$ and $\mathrm{SO}_{2}$ gases was recorded and a comparison between the different pellets was made.

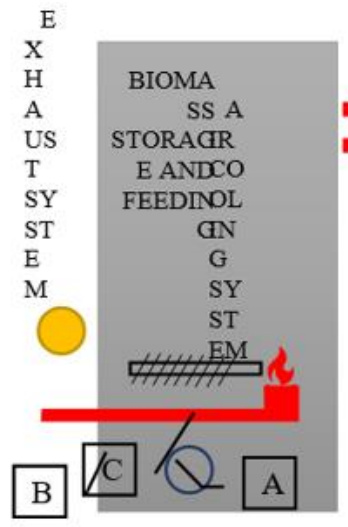

(a)

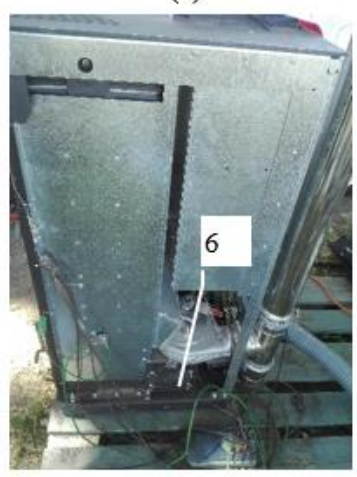

(c)

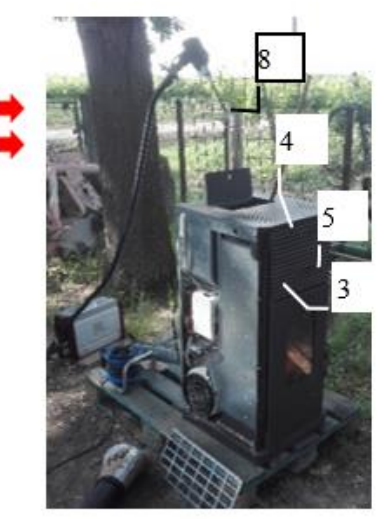

(b)

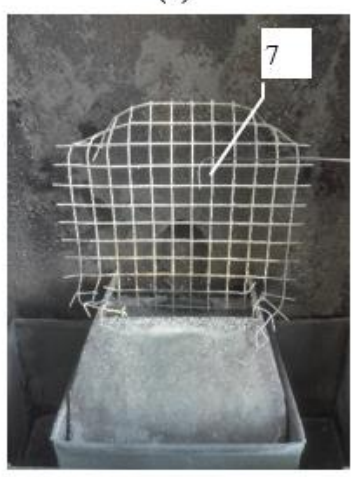

(d)
Figure 1. Scheme (a) and instrumentation of the wood pellet stove $(b, c, d)$

\subsection{Test methodology}

\subsubsection{Pellet chemical characterization}

Agri-pellets characterization started with the samples drying according to ASTM method [16] in order to assess the moisture content wet basis (Eq. (1)).

$$
M_{B I O, W B}=\frac{m_{B I O, w e t}-m_{B I O, d r y}}{m_{B I O, w e t}}
$$

The chemical composition of the different agri-pellets was characterized through the ultimate analysis, performed with a CHNS-O analyzer, that returns the percentage amount of 
carbon, hydrogen, nitrogen, sulfur and oxygen. The ash content was determined through a 6 hours muffle furnace calcination at $600^{\circ} \mathrm{C}$. The elemental analysis was used to calculate the biomass higher heating value according to the Channiwala-Parikh correlation [17] (Eq. (2)).

$$
\begin{gathered}
\mathrm{HHV}_{\mathrm{BIO}}=349.1 \mathrm{C}+1178.3 \mathrm{H}+100.5 \mathrm{~S}-103.40 \\
-15.1 \mathrm{~N}-21.1 \mathrm{ASH}
\end{gathered}
$$

\subsubsection{Combustion test procedure}

As mentioned above, the wood pellet stove has a nominal thermal power output of $9 \mathrm{~kW}_{\text {th }}$, which means that approximately $2 \mathrm{~kg}$ of pellets are needed for 1 hour of test. Since the availability of hemp-hurd derived pellets was limited, due to the lab-scale pelletizing facility, the maximum power output of the stove was set to $5 \mathrm{~kW}_{\text {th }}$, which resulted in a fixed biomass flowrate of $0.95 \mathrm{~kg} \mathrm{~h}^{-1}$. In this way, the tests could be carried out with a low quantity of biomass, that ranged from 0.65 to $1.00 \mathrm{~kg}$ for each test. Moreover, this quantity was enough to establish a steady state regime, useful to measure the efficiency of the device by varying the fuel type. Finally, the hopper size was reduced (Figure 2) in order to keep the feeding auger full during the tests, avoiding the voids in the fueling.

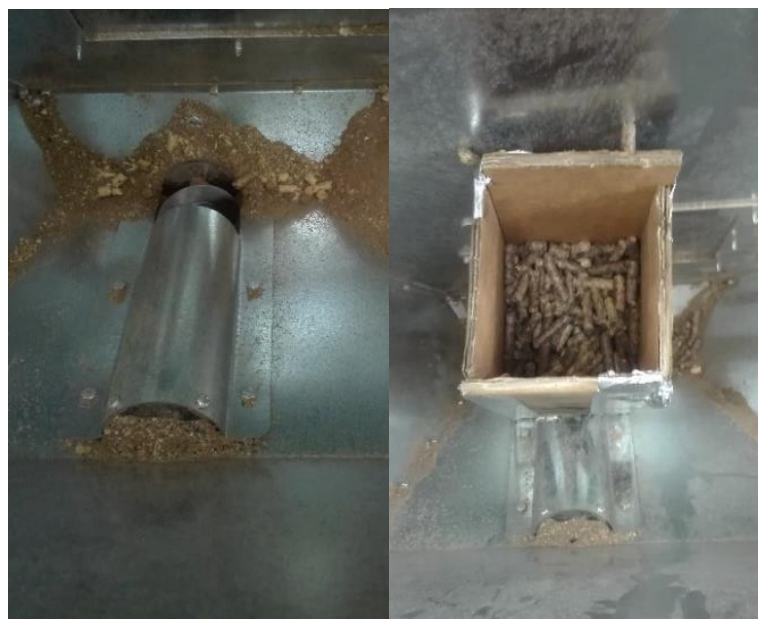

Figure 2. Standard hopper configuration (left) and modified hopper capacity (right)

Having said that, seven combustion tests were carried out during the experimental campaign and each of them followed the testing procedure listed below.

- The hopper of the stove was completely emptied and just the final part of the feeding auger was left full to avoid malfunction in the light-up procedure of the device.

- The fireplace was cleaned from the ashes and clinkers of the previous test;

- The selected quantity of pellet to be tested was put into the modified hopper;

- The stove was fired-up following the constructor procedure;

- Temperatures and emissions were automatically recorded every $10 \mathrm{~s}$, while the air flowrates were manually logged;

- During the startup, the stove follows several steps: ignition of the biomass, stabilization of the flame and then, starting from the power of $2 \mathrm{~kW}_{\text {th }}$ reaches the power of $5 \mathrm{~kW}_{\text {th }}$ in 5 minutes.
- The stove was shut down when the hopper was completely empty, and the next test was performed after a period of cooling down of the device.

\subsubsection{Efficiency calculation}

The wood pellet stove dissipates the combustion heat through radiation and natural convection from the hot surfaces (especially from the front glass door) and through forced convection by means of the air-cooling system represented in Figure 1a.

Since the natural convection and radiation is related to the estimation of several factors (e.g. view factors and convective heat transfer coefficients), which increases the uncertainty of the calculation, in this work, the comparison in terms of efficiency between the different biomasses was carried out by comparing the portion of heat transfer due to the air-cooling system. Hence, only the forced convection was considered and, for this reason, the reported efficiency (Eq. (3)) is not the overall efficiency of the device and is calculated as the ratio between the power dissipated by the air-cooling system and the power given by the stoichiometric combustion of the biomass.

$$
\begin{gathered}
\eta_{F C}=\frac{\dot{Q}_{F C}}{\dot{Q}_{B I O}} \\
\dot{Q}_{F C}=\dot{V}_{A I R} \cdot \rho_{A I R} \cdot c_{p, A I R} \cdot\left(T_{A I R, O U T}-T_{A I R, I N}\right) \\
\dot{Q}_{B I O}=\dot{m}_{B I O, d r y} \cdot H H V_{B I O} \\
m_{\text {BIO,dry }}=\mathrm{m}_{\text {BIO,wet }} \cdot\left(1-M_{B I O, W B}\right)
\end{gathered}
$$

Density and specific heat capacity of air were calculated according to the inlet and average temperature of the air respectively. In particular, the following equations were extrapolated from [18] and used for the calculation:

$$
\begin{gathered}
\rho_{A I R}=-2.673748 \cdot 10^{-14} \cdot T_{A I R, A V G}^{5}+4.77340 \cdot \\
10^{-12} \cdot T_{A I R, A V G}^{4}-3.56265 \cdot 10^{-8} \cdot T_{A I R, A V G}^{3}+ \\
1.53559 \cdot 10^{-5} \cdot T_{A I R, A V G}^{2}-4.75260 \cdot 10^{-3} \\
T_{A I R, A V G}+1.3 \\
c_{p, A I R}=-2.64444 \cdot 10^{-8} \cdot T_{A I R, I N}^{3}+6.81522 \\
\cdot 10^{-5} \cdot T_{A I R, I N}^{2}+1.40874 \cdot 10^{-1} \\
\cdot T_{A I R, I N}+951.71757
\end{gathered}
$$

\section{RESULTS}

As mentioned in the paragraph 2.3.2, during each test the stove went through a series of step: from the fire-up to the shutdown. To assess the performances of the stove it was important to determine a steady state period to calculate efficiency and emissions comparable between the different runs. In Figure 3 the complete combustion test of vineprunings derived pellet is shown. It is clear from the picture the existence of a steady state sector in the middle of the runtime which is used for efficiency and emissions calculations listed in the next paragraphs.

To have a broader view on the variations of the different pollutants, emissions results will be shown both averaged on the steady state period and averaged over the total runtime, including the startup and shutdown periods. 


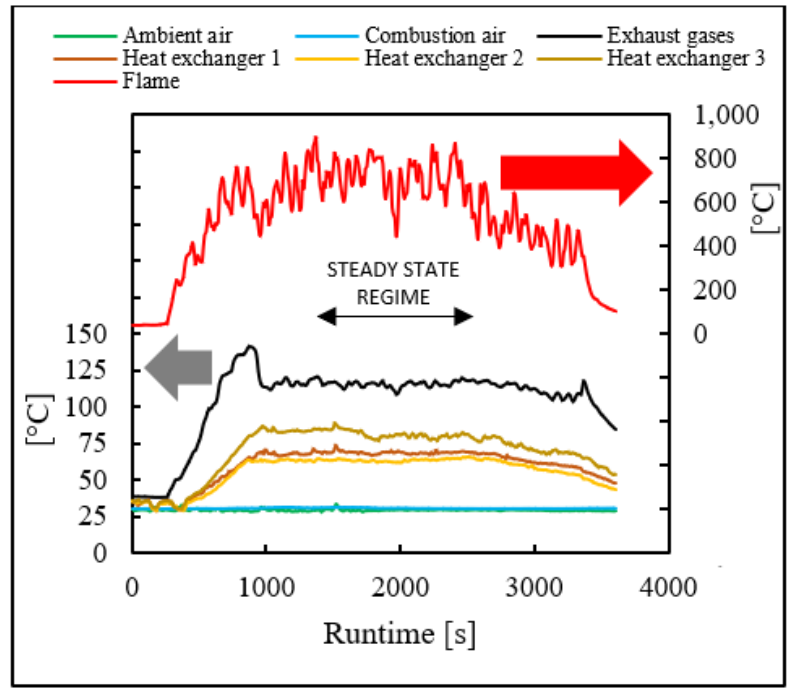

Figure 3. Temperatures variations over the entire combustion test of vine-prunings derived pellets

\subsection{Pellet characterization}

Table 2 resumes the results of the pellets characterization. The ultimate analysis for the commercial-grade pellet $\mathrm{A} 1+$ and A2 was not performed and the reported data are the ones provided by the producer.

Table 2. Pellet samples ultimate analysis, ash and moisture content, and calculated HHV

\begin{tabular}{|c|c|c|c|c|c|c|c|c|}
\hline ell & & & & & & & [\%] & $\begin{array}{r}\mathrm{H} \\
\mathrm{MJ}\end{array}$ \\
\hline $\mathrm{A} 1+$ & -- & -- & -- & -- & -- & $<05$ & 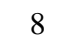 & 17.0 \\
\hline$\wedge 2$ & . & -- & -- & -- & -- & & $<10$ & $>16.5$ \\
\hline VINE & 46.4 & 6.5 & 0.9 & 0 & 42.6 & 3. & 10 & 19.3 \\
\hline Liv & 2 & 5.6 & & 0 & & & 10 & 6.7 \\
\hline EMP? & 31.0 & 4.6 & 0.6 & 0 & 30.4 & 33 & 13 & 12.3 \\
\hline HEMP & 46.4 & 4.0 & 0.5 & 0 & 41.7 & 7. & 1 & 16.4 \\
\hline HEMP15 & 32.5 & 4.8 & 0.7 & 0 & 26.9 & 35.1 & 7 & 13.4 \\
\hline
\end{tabular}

From the elemental and ash analyses it stands out the high ash quantity of the HEMP15GR, HEMP30GR and HEMP15. This result is in contrast with the ash content of the sample HEMP which is the base material for these mixtures. The increased ash content can be due to the overheating and degradation of the biomass during the processing: grinding and pelletization. Results shown hemp agri-pellets HHV ranging from 12 to $17 \mathrm{MJ} \mathrm{kg}^{-1}$. Instead, vine pruning pellets presented an HHV up to $20 \mathrm{MJ} \mathrm{kg}^{-1}$.

\subsection{Efficiency comparison}

The forced convection efficiency calculation is based on the measurement of the inlet and outlet temperatures of the airexhaust heat exchanger. In Figure 4 the average temperature, recorded in steady state regime, are reported for each sample combustion test. The three temperatures logged at the outlet of the heat exchanger were averaged and reported as Heat exchanger $A V G$.

Ambient and combustion air temperatures slightly increased during the tests due to weather conditions since the wood stove was installed outdoor for these tests.

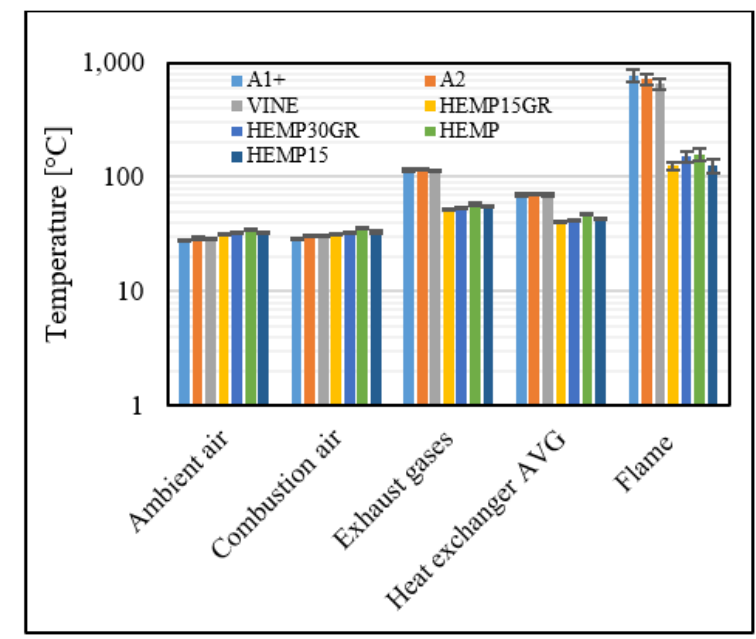

Figure 4. Average temperatures recorded during the tests at steady state conditions

$\mathrm{A} 1+, \mathrm{A} 2$ and VINE pellets shown similar results in terms of exhaust gases, heat exchanger AVG and flame temperatures.

On the contrary, hemp-hurd derived pellet shown lower combustion performances which resulted in far lower flame temperatures and, thus, in lower exhaust gas and heat exchanger ones. It can be seen from Figure 5 how the flame temperature rapidly decreased for hemp-derived pellets. This phenomenon is associated to the tendency of hemp pellets of clogging the fireplace (Figure 6) because the grate cleaner is not effective in removing it. This tendency was not reported in burning $\mathrm{A} 1+, \mathrm{A} 2$ and VINE pellets which generates softer ashes that can be disposed by the grate cleaner.

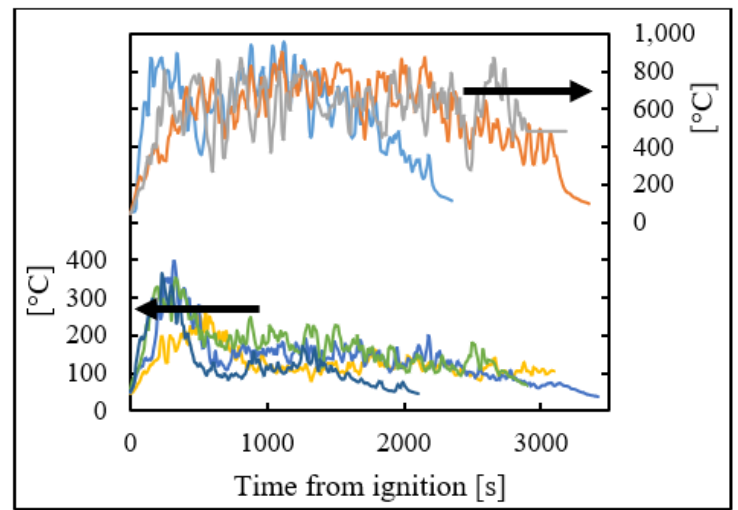

Figure 5. Flame temperatures over runtime

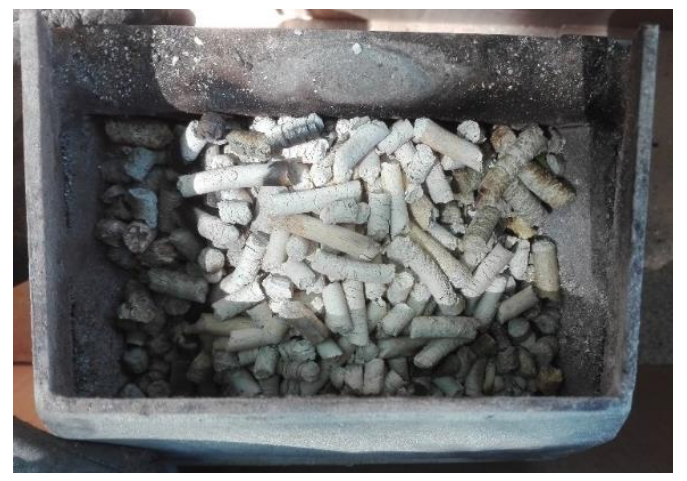

Figure 6. Ashes and unburnt hemp-hurd pellets in the fireplace of the wood stove at the end of the HEMP15GR combustion test 


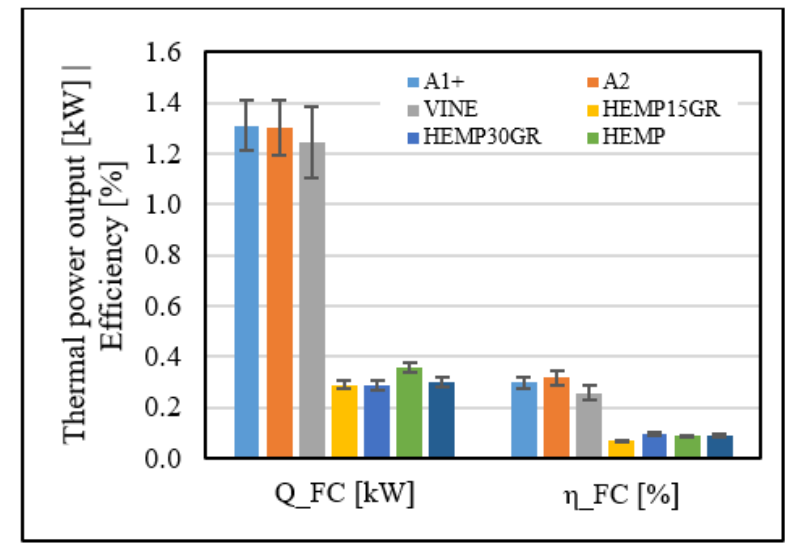

Figure 7. Thermal power gained at the heat exchanger and overall forced convection efficiency

Lower flame temperatures of the hemp-hurd derived pellets translate into lower heat available for the room heating ( $\left.\mathrm{Q}^{\prime} \mathrm{FC}\right)$ and lower efficiency conversion of the chemical energy contained in the biomass (Figure 7). For standard and vinepruning pellets, the thermal power recovered via forced convection at $5 \mathrm{~kW}_{\text {th }}$ nominal power output is approximately $1.3 \mathrm{~kW}_{\text {th }}$ : the $30 \%$ of the total available through the calculation of the different $\mathrm{HHV}_{\mathrm{BIO}}$. In the case of hemp-hurd derived pellets, the thermal power available for the room heating via forced convection is only near $0.3 \mathrm{~kW}_{\text {th }}$ which means an efficiency between 7 to $9 \%$.

\subsection{Emissions comparison}

The emission analyses are subdivided into two different graphs: Figure 7 reports the results of the emissions during the steady state regime at $5 \mathrm{~kW}_{\text {th }}$ power output set on the stove, while Figure 8 resumes the emission results of the entire run for each sample combustion test.

The emission analyses highlight the tendency of the $\mathrm{CO}$ and $\mathrm{NO}_{\mathrm{x}}$ emissions to increase as we move away from the gold standard of pellet A1+. Is also noticeable that the emissions increase by averaging the results on the entire test with respect to the steady state period. This can be ascribed to the presence of the startup period, characterized by poor combustion efficiency and strong smoke generation (Figure 10).

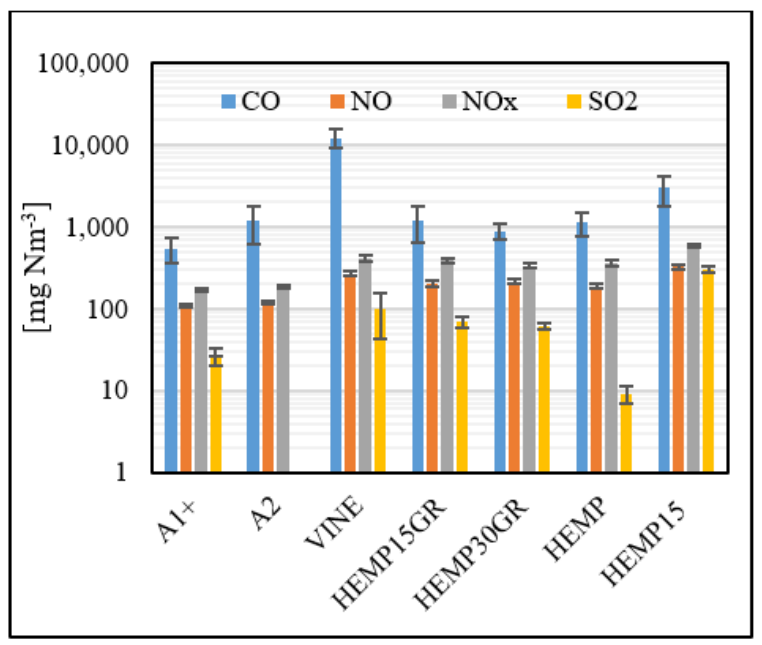

Figure 8. Emission results at $13 \% \mathrm{O}_{2}$ averaged in the period at steady state conditions

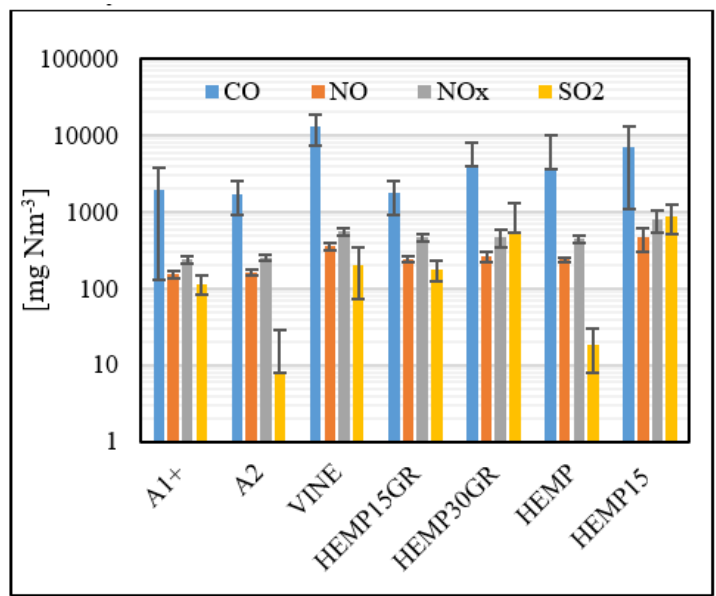

Figure 9. Emission results at $13 \% \mathrm{O}_{2}$ averaged on the entire combustion test

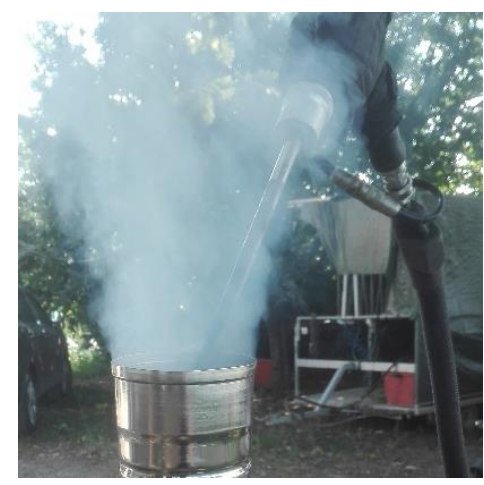

Figure 10. Smoke generation during the pellets ignition phase

As regards to the vine-pruning derived pellets, the emissions of $\mathrm{SO}_{2}$ are still comparable with the other samples, except for the excellent result of the pellet A2. This result shown that the phytosanitary treatments, on organic vineyard, based on cupric sulphate do not significantly increase the emissions of sulphur dioxide. On the other hand, CO emissions are one order of magnitude higher, in the case of vine derived pellets, respect to $\mathrm{A} 1+$ and $\mathrm{A} 2$ standards.

Hemp-hurd derived pellets shown consistent emission results that seems not to be influenced by the presence of sawdust in any percentage. As shown in the efficiency results, the issue of this material is the tendency of creating strong ashes that clog the fireplace of the stove, reducing the combustion efficiency and, thus, worsening the emissions of CO.

\section{CONCLUSIONS}

This work investigated the possibility to fuel a domestic pellet stove with agri-pellets derived from vine pruning and hemp processing in terms of combustion efficiency and polluting emissions. A1+ pellet confirmed to be the gold standard both for lowest emissions generation and for high efficiency in the combustion phase, giving force to the NorthItaly legislation that limits the combustion to this grade in specific areas.

From the tests emerges the good capability of the stove to handle vine-prunings derived pellets with the suggestion to increase the cleaning rate of the fireplace to allow the 
discharge of the higher ash production. However, CO emissions are 20-times higher for vine pellets if compared to A1+ standard. This result suggested that the stove combustion parameters and/or fireplace geometries should be modified in order to generate a cleaner combustion.

Hemp-hurd derived pellets shown a strong tendency to form stiff ash pellets that could not be removed by the grate cleaner and worsen the combustion efficiency of the stove. Emission results were slightly higher than $\mathrm{A} 1+$ but a real comparison could not be made since hemp-hurd pellets burned in different conditions due to ashes deposition. The collected date suggested that hemp-hurd derived pellets are not suitable for this kind of domestic pellet stove and that a dedicated ash extraction mechanism is needed.

\section{ACKNOWLEDGMENT}

This work was funded by the Italian project UNIHEMP utilizzo di biomassa da canapa industriale per la produzione di energia e nuovi biochemicals (cod. ars01_00668) - presentato in risposta all'avviso pubblico prot. n. 1735 del 13/07/2017 emanato dal MIUR (Ministero dell'Istruzione, dell'Università e della Ricerca) - è finanziato dal fondo europeo di sviluppo regionale (FESR) nell'ambito del PON R\&I 2017-2020 - asse 2 - azione ii - os 1.b) (decreto di concessione prot. n. 2016 del 27/07/2018)

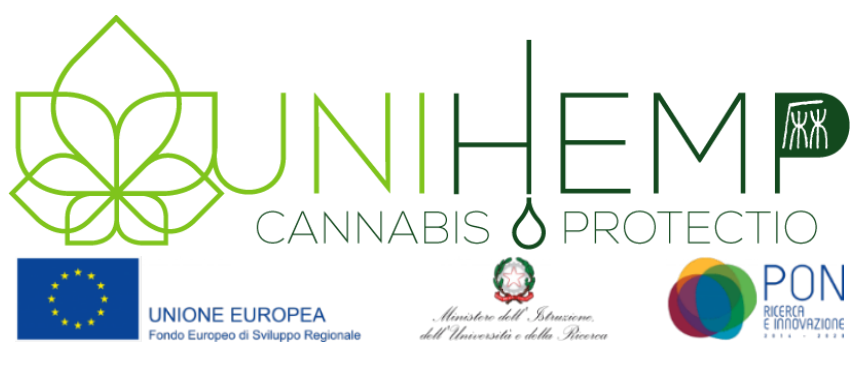

\section{REFERENCES}

[1] Allesina, G., Pedrazzi, S., Allegretti, F., Morselli, N., Puglia, M., Santunione, G., Tartarini, P. (2018). Gasification of cotton crop residues for combined power and biochar production in Mozambique. Applied Thermal Engineering, 139: 387-394. https://doi.org/10.1016/j.applthermaleng.2018.04.115

[2] Puglia, M., Morselli, N., Tartarini, P. (2019). Design and first tests of a micro lab scale $(2 \mathrm{~kg} / \mathrm{h})$ gasifier. European Biomass Conference and Exhibition Proceedings, pp. 797-801. https://doi.org/10.5071/27thEUBCE2019. 2CV.2.12

[3] Santunione, G., Bigi, A., Puglia, M., Morselli, N., Sebastianelli, L., Tartarini, P. (2019). Study of copper content distribution through the thermochemical conversion chain of vine pruning biomass. European Biomass Conference and Exhibition Proceedings, pp. 1952-1956. https://doi.org/10.5071/27thEUBCE2019ICV.1.9

[4] Morselli, N., Puglia, M., Parenti, M., Tartarini, P. (2019). Use of Fabric Filters for syngas dry filtration in smallscale gasification power systems. AIP Conference Proceedings, 2191: 020117 https://doi.org/10.1063/1.5138850

[5] Morselli, N., Puglia, M., Mason, J., Parenti, M., Ottani,

F., Tartarini, P. (2019). Experimental and modeling evaluation of possible solutions for compact design of producer gas heat exchangers. Journal of Physics: Conference Series, University of Padova, Italy.

[6] Allesina, G., Pedrazzi, S., Puglia, M., Morselli, N., Allegretti, F., Tartarini, P. (2018). Gasification and wine industry: Report on the use vine pruning as fuel in small -scale gasifiers. European Biomass Conference and Exhibition Proceedings, 26thEUBCE, pp. 722-725. https://doi.org/10.5071/26thEUBCE2018-2CV.2.19

[7] Pedrazzi, S., Allesina, G., Morselli, N., Puglia, M., Barbieri, L., Lancellotti, I., Ceotto, E., Cappelli, G.A., Ginaldi, F., Giorgini, L., Malcevschi, A., Pederzini, C., Tartarini, P. (2017). The energetic recover of biomass from river maintenance: The rebaf project. European Biomass Conference and Exhibition Proceedings, 25thEUBCE, pp. 52-57. https://doi.org/10.5071/25thEUBCE2017-1AO.7.3

[8] Barella, P.A. (2010). L'uso energetico dei sarmenti della vite - valutazioni tecnico economiche di filiere significative in provincia di Treviso, Veneto Agricoltura.

[9] Picchi, G., Silvestri, S., Cristoforetti, A. (2013). Vineyard residues as a fuel for domestic boilers in Trento Province (Italy): Comparison to wood chips and means of polluting emissions control. Fuel, 113: 43-49. https://doi.org/10.1016/j.fuel.2013.05.058

[10] Puglia, M., Pedrazzi, S., Allesina, G., Morselli, N., Tartarini, P. (2017). Vine prunings biomass as fuel in wood stoves for thermal power production. International Journal of Heat and Technology, 35(1): S96-S101. https://doi.org/10.18280/ijht.35Sp011

[11] PAIR2020 - Piano Aria Integrato. Emilia-Romagna (IT) regional law n.14 / 22 October 2018.

[12] CAEB International Srl. www.caebinternational.it, accessed on Mar. 15, 2020.

[13] Testo Instruments. www.testo.com, accessed on Mar. 15, 2020.

[14] Pico Technology. www.picotech.com, accessed on Mar. $15,2020$.

[15] MRU Italia Srl, www.mru.it, accessed on Mar. 15, 2020.

[16] ASTM. (1995). E1756-08 standard test method for ash in biomass. ASTM International, West Conshohocken, PA. https://doi.org/10.1520/E1756-08

[17] Basu, P. (2010). Biomass Gasification and Pyrolysis, Practical Design. 1-25. https://doi.org/10.1016/B978-012-374988-8.00001-5

[18] Cengel, Y.A. (1997). Introduction to Thermodynamics and Heat Transfer. McGraw-Hill.

\section{NOMENCLATURE}

$M$

$m$

$H H V$

C

$H$

S

$O$

$N$

ASH

$\dot{Q}$

$\dot{V}$

$\rho$
Moisture content of the biomass

Mass, kg

Higher heating value, $\mathrm{J} \mathrm{kg}^{-1}{ }^{\circ} \mathrm{C}^{-1}$

Carbon content, \%

Hydrogen content, \%

Sulfur content, \%

Oxygen content, $\%$

Nitrogen content, \%

Ash content, \%

Thermal power output, $\mathrm{W}$

Volumetric flowrate, $\mathrm{m}^{3} \mathrm{~h}^{-1}$

Density, $\mathrm{kg} \mathrm{m}^{-3}$ 


\begin{tabular}{|c|c|c|c|}
\hline$c_{p}$ & Specific heat capacity, $\mathrm{J} \mathrm{kg}^{-1}{ }^{\circ} \mathrm{C}^{-1}$ & dry & Referred to a dry sample \\
\hline$T$ & Temperature, ${ }^{\circ} \mathrm{C}$ & wet & Referred to a moist sample \\
\hline \multirow[t]{2}{*}{$\mathrm{Nm}^{3}$} & Normal cubic meter, measured at $0^{\circ} \mathrm{C}$ and & $W B$ & Wet-basis \\
\hline & $1.0325 \mathrm{bar}$ & $O U T$ & $\begin{array}{l}\text { Value referred to the outlet of the air- } \\
\text { cooling system }\end{array}$ \\
\hline Greek symbols & & $I N$ & $\begin{array}{l}\text { Value referred to the inlet of the air- } \\
\text { cooling system }\end{array}$ \\
\hline$\eta$ & Efficiency & $A V G$ & Average \\
\hline
\end{tabular}

\section{Subscripts}

$B I O$

$F C$
Referred to the biomass

Forced convection

\section{APPENDIX}

In the following tables are reported the data relative to Figure 4, Figure 7, Figure 8 and Figure 9 respectively.

Table 3. Temperature data of Figure 4

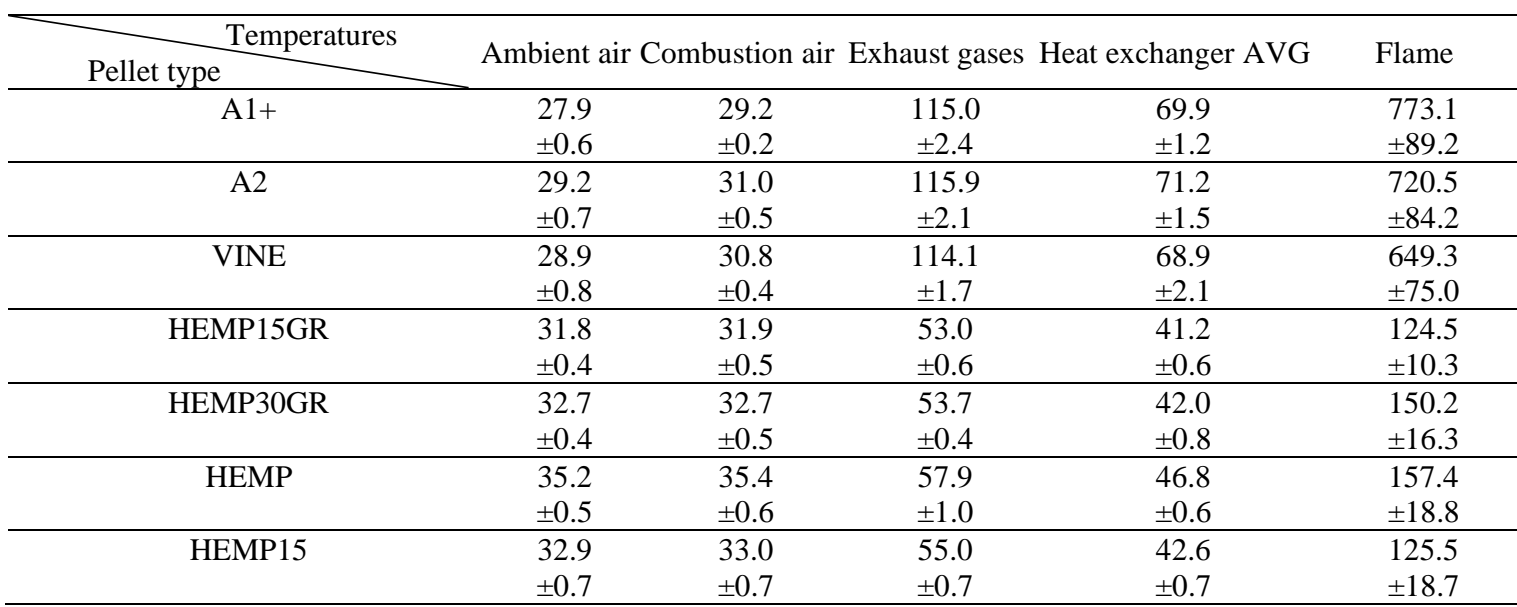

Table 4. Data of Figure 7

\begin{tabular}{|c|c|c|c|c|c|c|}
\hline \multirow{2}{*}{ Pellet type } & \multicolumn{3}{|c|}{ QFC $[\mathrm{kW}]$} & \multicolumn{3}{|c|}{$\eta_{\mathrm{FC}}[\%]$} \\
\hline & 1.312 & \pm & 0.098 & $29.7 \%$ & \pm & $2.2 \%$ \\
\hline $\mathrm{A} 2$ & 1.303 & \pm & 0.106 & $31.6 \%$ & \pm & $2.6 \%$ \\
\hline VINE & 1.245 & \pm & 0.143 & $25.8 \%$ & \pm & $3.0 \%$ \\
\hline HEMP15GR & 0.290 & \pm & 0.016 & $6.9 \%$ & \pm & $0.4 \%$ \\
\hline HEMP30GR & 0.286 & \pm & 0.020 & $9.3 \%$ & \pm & $0.7 \%$ \\
\hline HEMP & 0.356 & \pm & 0.019 & $8.7 \%$ & \pm & $0.5 \%$ \\
\hline HEMP15 & 0.300 & \pm & 0.020 & $9.0 \%$ & \pm & $0.6 \%$ \\
\hline
\end{tabular}

Table 5. Data of Figure 8

\begin{tabular}{|c|c|c|c|c|}
\hline \multicolumn{5}{|l|}{ Pollutants } \\
\hline \multicolumn{5}{|r|}{$\mathrm{Nm}^{-3} @ 13 \% \mathrm{O}_{2}$} \\
\hline \multirow[t]{2}{*}{$\mathrm{A} 1+$} & 540 & 108 & 168 & 27 \\
\hline & \pm 184 & \pm 4 & \pm 6 & \pm 6 \\
\hline \multirow[t]{2}{*}{ A2 } & 1203 & 122 & 187 & 0 \\
\hline & \pm 582 & \pm 6 & \pm 9 & \pm 0 \\
\hline \multirow[t]{2}{*}{ VINE } & 12170 & 270 & 417 & 101 \\
\hline & \pm 3182 & \pm 21 & \pm 33 & \pm 57 \\
\hline \multirow[t]{2}{*}{ HEMP15GR } & 1201 & 202 & 393 & 69 \\
\hline & \pm 551 & \pm 16 & \pm 25 & \pm 10 \\
\hline \multirow[t]{2}{*}{ HEMP30GR } & 890 & 215 & 336 & 62 \\
\hline & \pm 193 & \pm 13 & \pm 24 & \pm 5 \\
\hline \multirow[t]{2}{*}{ HEMP } & 1151 & 189 & 364 & 9 \\
\hline & \pm 368 & \pm 15 & \pm 27 & \pm 2 \\
\hline \multirow[t]{2}{*}{ HEMP15 } & 2964 & 323 & 592 & 300 \\
\hline & \pm 1208 & \pm 20 & \pm 32 & \pm 28 \\
\hline
\end{tabular}


Table 6. Data of Figure 9

\begin{tabular}{ccccc}
\hline Pollutants & & & \\
Pellet type & $\mathrm{CO}\left[\mathrm{mg} \mathrm{Nm}^{-3} @ 13 \% \mathrm{O}_{2}\right] \mathrm{NO}\left[\mathrm{mg} \mathrm{Nm}^{-3} @ 13 \% \mathrm{O}_{2}\right] \mathrm{SO}_{\mathbf{x}}\left[\mathrm{mg} \mathrm{Nm}^{-3} @ 13 \% \mathrm{O}_{2}\right] \mathrm{SO}_{2}\left[\mathrm{mg} \mathrm{Nm}^{-3} @ 13 \% \mathrm{O}_{2}\right]$ \\
\hline $\mathrm{A} 1+$ & 1977 & 155 & 240 & 117 \\
& \pm 1847 & \pm 18 & \pm 28 & \pm 31 \\
\hline $\mathrm{A} 2$ & 1719 & 163 & 250 & 8 \\
& \pm 817 & \pm 14 & \pm 21 & \pm 21 \\
\hline VINE & 12954 & 362 & 557 & 206 \\
& \pm 5591 & \pm 39 & \pm 60 & \pm 133 \\
\hline HEMP15GR & 1759 & 242 & 461 & 175 \\
& \pm 825 & \pm 23 & \pm 48 & \pm 52 \\
\hline HEMP30GR & 3928 & 261 & 476 & 547 \\
& \pm 3945 & \pm 40 & \pm 124 & \pm 735 \\
\hline HEMP & 3595 & 238 & 445 & \pm 11 \\
& \pm 6291 & \pm 20 & \pm 44 & 881 \\
\hline HEMP15 & 6948 & 465 & 792 & \pm 357 \\
& \pm 5877 & \pm 161 & \pm 246 & \\
\hline
\end{tabular}

